ICHEU 2021

International Conference «Humanity in the Era of Uncertainty»

\title{
COVID-19 PANDEMIC AS AN UNCERTAIN SITUATION: BEHAVIOURAL COPING AMONG STUDENTS
}

\author{
Elena Semenovna Sinelnikova (a)* \\ *Corresponding author \\ (a) Saint-Petersburg State Transport University, 190031 Saint Petersburg, 9 Moskovsky pr., Saint-Petersburg, Russia, \\ elena.sinelni@yandex.ru
}

\begin{abstract}
Uncertainty has been one of the key characteristics of COVID-19 Pandemic, especially at the initial part. Different aspects of the situation were uncertain: from probable duration of the pandemic, treatment, and prevention methods to the length of the restrictive measures and their economic impact. Uncertainty of the situation as well as rapid social changes contributed to increased stress levels and impaired psychological functioning. The purpose of the study was to investigate behavioural coping on self-isolation among student with different levels of situational life satisfaction. 100 students (59\% female, $41 \%$ male) aged 17 to 27 (M $=19.4, \mathrm{SD}=1.48)$ from Saint-Petersburg State Transport University, Russia, participated in the qualitative study. The authors' questionnaire was applied. The questionnaire included questions on what changes have taken place in participants lives, and what they lacked in self-isolation and what they were doing to make up for this lack. Participants rated their situational life satisfaction level on a 7-point Likert scale. Results have shown that behavioral coping with the situation was focused on mutual social support, care for participants' health and physical form, self-development, self-organization, taking care of the home and running the household. Running the household was applied only by students with a high and average level of situational life satisfaction. And self-organization was applied exclusively by students with a high level of situational life satisfaction which demonstrates that these forms of coping make important contribution to situational life satisfaction. Self-organization was accompanied with feelings of joy, freedom, and control over one's life.
\end{abstract}

2357-1330 C 2021 Published by European Publisher.

Keywords: COVID-19, self-isolation, coping, life satisfaction 


\section{Introduction}

COVID-19 pandemic caused an increased level of stress and impaired psychological functioning of people in different regions of the world (Gill et al., 2021; Kavčič et al., 2021; Szabo et al., 2020). These effects have to do with a range of characteristics of the pandemic: suddenness of COVID-19 outbreak, threat for health and live, fear and anxiety (Locada-Baltazar et al., 2020), a huge amount of information about COVID-19 (Locada-Baltazar et al., 2020), uncertainty, and rapid social changes (Kubo et al., 2021). Uncertainty has been the key characteristic of the COVID-19 pandemic. Different aspects of the situation were uncertain: probable duration of the pandemic, treatment, and prevention methods, length of the restrictive methods, economic and social impact. Uncertainty combined with limited capacities to control over the situation was a serious stress-factor.

Fear was the most prevalent emotion at the initial part of COVID-19 outbreak (Seçer \& Ulaş, 2020). Anger, irritability, loneliness also were quite common among quarantined participants (Röhr et al., 2020). Earlier research on emotional responses to quarantine has shown that it causes emotional responses that do differ in its depth and duration: from anger, boredom and irritation to mental health deterioration, emotional exhaustion, and depression (Brooks et al., 2020).

Many studies focus on social and personal resources of coping with COVID-19 pandemic and quarantine (self-isolation) (Margetic et al., 2021; Liang et al., 2020; Locada-Baltazar et al., 2020). Crosscultural study with participants from Russia, Kyrgyzstan and Peru has shown that participants from all included in the study cultural contexts apply all major coping strategies, the most common ones were active coping, acceptance, planning, positive reinterpretation (Denisse et al., 2020).

Social support, mutual social support within the family, decrease in emotional distress are considered by researchers as an important social resource for quarantined and self-isolated people (LocadaBaltazar et al., 2020; Margetic et al., 2021).

Daily experience of positive emotions, the quality of sleep, the higher level of perceived selfeffectiveness reduces emotional distress among quarantined people. Higher expressed negative emotions towards people, feeling of loneliness are associated with a higher level of emotional distress in Spain (Losada-Baltar et al., 2020).

Kubo et al. (2021) have shown that ego-resiliency contributed to coping with stress in Japan. Egoresiliency was associated with decreased depression symptoms among participants with a high level of selfrestriction during the pandemic (Kubo et al., 2021). Active coping contributed to a decreased level of distress and avoiding coping led to increased level of distress in Croatia (Margetic et al., 2021).

Coping strategies employed in the pandemic had not only short-term but also longer-term consequences. Liang et al. (Liang et al., 2020) revealed that the role of distress in post-traumatic stress disorder development was mediated by negative coping (Liang et al., 2020)

In general research on coping strategies during COVID-19 pandemic has shown positive outcomes of flexible and active coping, positive emotions, and social support for dealing with stress, distress, and depression.

However empirical studies focused on life satisfaction during pandemic are quite rare. Talevi et al. (2020) have shown that life satisfaction decreased during the pandemic. Self-compassion was positively 
associated with life satisfaction (Li et al., 2021). Existential anxiety and life satisfaction mediated a positive effect of post-traumatic stress on posttraumatic growth. Post-traumatic stress led to post-traumatic anxiety growth among participants with a high level of situational life satisfaction (Tomaszek \& MuchackaCymerman, 2020). There is little research on psychological factors of life-satisfaction during pandemic. Behavioural coping strategies applied by participants with different level of situational life satisfaction have hardly been studied. In addition, there is little qualitative research focused on coping and life-satisfaction during the pandemic.

\section{Problem Statement}

There is little research on psychological factors of life-satisfaction during pandemic. Behavioural coping strategies applied by participants with different levels of situational life satisfaction have hardly been studied. In addition, there is little qualitative research focused on coping and life-satisfaction during the pandemic.

\section{Research Questions}

3.1. Which forms of behavioural coping did students apply on self-isolation?

3.2. Which forms of coping were applied by participants with high and low levels of situational life satisfaction?

\section{Purpose of the Study}

The purpose of the current study was to examine which behaviours were used by students with different levels of situational life satisfaction to cope with the pandemic and to identify behavioural coping applied by students with high levels of life satisfaction.

\section{Research Methods}

\subsection{Method}

The authors' questionnaire was applied. We asked participants to answer open questions: "What changes have happened in your life after the outbreak of the pandemic and the introduction of lockdown?" "Which of these changes are you happy with?", "Do you do anything to make up for what you lack for? If yes, what?"

Situational life-satisfaction was measured by 1-item "To what extent are you satisfied with your life now? Please rate on a 7-point Likert scale (1 - not at all, 7 - very much)", "If you want to write some more about the current situation, about your feelings, how you deal with the situation, please, do it". The questionnaire also contained some demographic questions about participants' age, gender, location, current personal situation (decline of income, relatives who had to work offline, friend or relatives who had COVID-19 or viral pneumonia). 


\subsection{Participants}

100 full time students of Emperor Alexander I Saint-Petersburg State Transport University, SaintPetersburg, Russia (59\% female, 41\% male) aged from 17 to $27(\mathrm{M}=19,4, \mathrm{SD}=1,48)$ participated in the study. The data was collected from 21.04.2020 to 11.05.2020. Russia had been in lockdown since 30.03.2020, students were on distance learning. 42\% participants left Saint-Petersburg after transition to distance learning. At the time of survey, they lived in different regions of Russia. $40 \%$ of participants indicated decline in their own or family income.

\section{Findings}

Participants were divided into 3 groups according to their answers to the question "To what extent are you satisfied with your life now? Please rate on 7-point Likert scale (1- not at all, 7-very much)": high (5-7 points on the 7-point Likert scale), average (4 points), low (2-3 points) levels of situational life satisfaction (table 1).

Table 1. Situational life satisfaction among students on self-isolation

\begin{tabular}{cccc}
\hline & Low level & Average level & High level \\
\hline$\%$ of students & $32 \%$ & $23 \%$ & $45 \%$ \\
\hline
\end{tabular}

Based on a qualitative analysis of respondents' answers to the question: "Do you do anything to make up for what you lack for? If yes, what?" we identified the following behavioural coping. They were communication and mutual social support within the family or couple at home; electronic communication with friends, relatives, or girlfriend $\backslash$ boyfriend; taking care of their health and physical condition. In addition these were self-development: acquiring new skills, learning foreign languages, painting; running the household: cooking, cleaning, organizing domestic space; self-organization. The frequency of mention ( $\%$ of participants) of this form of behavioural coping is described in table 2.

Table 2. Behavioral coping among students with different levels of situational life satisfaction (frequency of mention, \% of participants in each group)

\begin{tabular}{ccccc}
\hline Behavioural coping & Low level & Average level & High level & Total scores \\
\hline $\begin{array}{c}\text { Communication and } \\
\text { mutual support at } \\
\text { home. }\end{array}$ & $37.5 \%$ & $21.7 \%$ & $37.7 \%$ & $34 \%$ \\
$\begin{array}{c}\text { Communication and } \\
\text { mutual support via } \\
\text { electronic means. }\end{array}$ & $46.9 \%$ & $47.8 \%$ & $35.5 \%$ & $42 \%$ \\
$\begin{array}{c}\text { Taking care of their } \\
\text { health and physical } \\
\text { condition. }\end{array}$ & $34.3 \%$ & $39.1 \%$ & $37.7 \%$ & $37 \%$ \\
$\begin{array}{c}\text { Self-development. } \\
\text { Running the } \\
\text { household. }\end{array}$ & $21.9 \%$ & $52.2 \%$ & $42.2 \%$ & $38 \%$ \\
Self-organization & $3.1 \%$ & $17.4 \%$ & $24.4 \%$ & $16 \%$ \\
\hline
\end{tabular}




\section{Conclusion}

Results have shown that mutual social support, taking care over their health and physical condition and self-development, was the most common form of behavioural coping with self-isolation among students.

Communication and mutual social support are important coping resources for participants with different levels of situational life satisfaction. Almost identical frequent references of mutual social support within the family by participants with a high and low level of situational life satisfaction indicate that it did not make a major contribution to situational life satisfaction in self-isolation. More frequent references of communication via electronic means by participants with low and average levels of situation life satisfaction may indicate its compensatory role.

Taking care of their health, physical condition was a behavioural coping, which has been written almost equally often by participants with high, average, and low levels of situational life satisfaction. This form of behavioural coping is related to several needs important in the pandemic situation: health strengthen, physical activity.

Participants with different levels of situational life satisfaction applied self-development as behavioural coping. However, students with average and high levels indicated that they were involved in self-development much more often than students were with a low level of situational life satisfaction. For some participants with a low level of situational life satisfaction, self-development has become an additional source of stress due to overwork.

Running the household was a relatively rare form of behavioural coping among students, which was applied almost exclusively by students with high and average level of situational life-satisfaction. This indicates that running the household contributes to life-satisfaction. Running the household allowed participants to take control cover domestic space, enjoy tasty meals, which contributes to the experience of positive emotions and organizing one's life.

Self-organization also was relatively rare behavioural coping among students. Almost all students who have organized their life responded that they had a high level of situational life satisfaction. Participants associated self-organization with feelings of joy and freedom, which they experienced despite the restrictions. Successful distance learning imposed greater demands on self-organization. Self-organization allowed students to take control over their life, to increase efficiency of studying and to devote time to other areas of life that are important to them. Perceived control contributes to psychological distancing towards pandemic (Zheng et al., 2020). Perceived self-effectiveness and daily experience of positive emotions decreases distress (Losada-Baltar et al., 2020). The study revealed that forms of behavioural coping related to organizing participants live on self-isolation made the most important contribution to situational lifesatisfaction during self-isolation.

\section{References}

Brooks, S. K., Webster, R. K., Smith, L. E., Woodland, L., Wessely, S., Greenberg, N., \& Rubin, G. J. (2020). The psychological impact of quarantine and how to reduce it: rapid review of the evidence. The lancet, 395(10227), 912-920. https://doi.org/10.1016/S0140-6736(20)30460-8 
Denisse, M. M., Bertha, M. R. R., Oscar, M. P., \& Nataly, F. R. (2020). Coping Responses During the COVID-19 Pandemic: A Cross-Cultural Comparison of Russia, Kyrgyzstan, and Peru. Psychology in Russia: State of the art, 13(4), 55-74. https://doi.org/10.11621/pir.2020.0404

Gill, P. K., Du, C., Khan, F., Karimi, N., Sabharwal, K., \& Agarwal, M. (2021). The psychological effects of COVID-19 spread in young Canadian adults. International Journal of Social Psychiatry, 0020764020988878. https://doi.org/10.1177/0020764020988878

Kavčič, T., Avsec, A., \& Kocjan, G. Z. (2021). Psychological functioning of Slovene adults during the COVID-19 pandemic: does resilience matter? Psychiatric Quarterly, 92(1), 207-216. https://doi.org/10.1007/s11126-020-09789-4

Kubo, T., Sugawara, D., \& Masuyama, A. (2021). The effect of ego-resiliency and COVID-19-related stress on mental health among the Japanese population. Personality and Individual Differences, 175, 110702. https://doi.org/ 10.1016/j.paid.2021.110702

Li, A., Wang, S., Cai, M., Sun, R., \& Liu, X. (2021). Self-compassion and life-satisfaction among Chinese self-quarantined residents during COVID-19 pandemic: A moderated mediation model of positive coping and gender. Personality and individual differences, 170, 110457. https://doi.org/10.1016/j.paid.2020.110457

Liang, L., Gao, T., Ren, H., Cao, R., Qin, Z., Hu, Y., Li, C., \& Mei, S. (2020). Post-traumatic stress disorder and psychological distress in Chinese youths following the COVID-19 emergency. Journal of health psychology, 25(9), 1164-1175. https://doi.org/10.1177/1359105320937057

Losada-Baltar, A., Jimenez-Gonzalo, L., Gallego-Alberto, L., Sequeros Pedroso-Chaparro, FernandesPires J., Márquez-González, M. (2020). "We're staying at home". Association of self-perceptions of aging, Personal and family resources and loneliness with psychological distress during the lockdown period of COVID-19. Gerontol B Psychol Sci Soc Sci, 76(2), 10-16. https://doi.org/10.1093/geronb/gbaa048

Margetic, B., Peraica, T., Stojanovic, K., \& Ivanec, D. (2021). Predictors of emotional distress during the COVID-19 pandemic; a Croatian study. Personality and Individual Differences, 175, 110691. https://doi.org/10.1016/j.paid.2021.110691

Röhr, S., Müller, F., Jung, F., Apfelbacher, C., Seidler, A., \& Riedel-Heller, S. G. (2020). Psychosocial impact of quarantine measures during serious coronavirus outbreaks: a rapid review. Psychiatrische Praxis, 47(4), 179-189. https://doi.org/10.1055/a-1159-5562

Seçer, İ., \& Ulaş, S. (2020). An investigation of the effect of COVID-19 on OCD in youth in the context of emotional reactivity, experiential avoidance, depression and anxiety. International journal of mental health and addiction, 1-14. https://doi.org/ 10.1007/s11469-020-00322-z

Szabó, C., Pukánszky, J., \& Kemény, L. (2020). Psychological effects of the COVID-19 pandemic on Hungarian adults. International journal of environmental research and public health, 17(24), 9565. https://doi.org/10.3390/ijerph17249565

Talevi, D., Socci, V., Carai, M., Carnaghi, G., Faleri, S., Trebbi, E., Bernardo, Di. A., Capelli, F., \& Pacitti, F. (2020). Mental health outcomes of the CoViD-19 pandemic. Rivista di psichiatria, 55(3), 137144. https://doi.org/10.1708/3382.33569

Tomaszek, K., \& Muchacka-Cymerman, A. (2020). Thinking about my existence during COVID-19, I feel anxiety and awe-The mediating role of existential anxiety and life satisfaction on the relationship between PTSD symptoms and post-traumatic growth. International journal of environmental research and public health, 17(19), 7062. https://doi.org/10.3390/ijerph17197062

Zheng, L., Miao, M., \& Gan, Y. (2020). Perceived control buffers the effects of the COVID-19 pandemic on general health and life satisfaction: The mediating role of psychological distance. Applied Psychology: Health and Well-Being, 12(4), 1095-1114. https://doi.org/10.1111/aphw.12232 